\title{
Variability of tidal current, density stratification and tidal flat sediment in a tidal river
}

\author{
K. Kawanishi \\ Department of Civil and Environmental Engineering, \\ Graduate School of Engineering, Hiroshima University, Japan
}

\begin{abstract}
Long-duration observations of tidal currents, stratification, and suspended sediment (SS) were conducted using moored acoustic Doppler current profilers (aDcps) and CTDs in the Ohta flood-way where flow and density conditions change significantly. Spatial variation of SS transport was examined from simultaneous measurements at longitudinal two places (Sta. A and B), which are located in about $2.8 \mathrm{~km}$ and $5.8 \mathrm{~km}$ upstream from the mouth. The deployment period of one month allowed us to examine the effect of a flood incident, wind, and both semi-diurnal and neap/spring aspects of tides. The data revealed a semi-diurnal stratification cycle driven by tidal straining of freshwater-induced horizontal density gradient at Sta. A. The tidal straining and the nonlinearity of tidal wave bring about the asymmetry of tidal current. The direction of net transport was upstream at Sta. A and downstream at Sta. B for the restricted freshwater discharge. Additional surveys were made to examine particle size distributions of the tidal flat sediment from 1 September 2004 to 28 January 2005.

Keywords: suspended sediment, sediment transport, tidal current, tidal straining, stratification, sound scatter, tidal estuary.
\end{abstract}

\section{Introduction}

Since estuaries often lie within regions of high population and industrial activity, the effects of discharged waste on the water quality, biological productivity, and the diversity of species in estuaries have become a topic of increasing concern. The suspended sediment (SS) in estuaries play a significant role in understanding ecological and engineering problems. The flow in tidal estuaries is very complex, particularly due to tidal oscillations associated with changes in the water depth, 
mean velocity, direction of flow and density gradients affected by salt and heat, so that our knowledge for the behavior is insufficient. Long-duration measurements of velocity, density and SS concentration profile are required so that semi-diurnal, fortnightly and seasonal timescales are addressed. However, most observations of $\mathrm{SS}$ in a tidal river have been restricted to short durations of the tidal cycle because it is difficult that the distribution of SS concentration is continuously measured.

Acoustical techniques can now provide extensive and detailed combined observations of current velocity and concentration of suspended particulate matter. Acoustic Doppler current profilers (aDcps) can be calibrated to provide data of the relevant quality and quantity (e.g. Holdaway et al [1]; Hill et al [2]), although such calibrations could benefit from more detailed measurements of particle size (Thorne et al [3]).

In the present study, long-duration observations of tidal currents, density stratification, SS concentration and tidal flat sediment were conducted in the Ohta floodway where flow and stratification conditions change significantly.

\section{Study area and measurements}

\subsection{Study area}

As shown in Figure 1(a), the Ohta River bifurcates into some branches in the Hiroshima delta before discharging to the Hiroshima Bay, and the Ohta flood-way in which there are observation stations is located on the west side of the Hiroshima delta. The Ohta estuary is tidally dominated; the tidal range of an extreme spring tide is about $4 \mathrm{~m}$. The freshwater runoff from the Gion sluice, which is located at about $9 \mathrm{~km}$ upstream from the mouth, is usually limited to about $10 \%$ of the Ohta River discharge. The salt water in this estuary can intrude to about $15 \mathrm{~km}$ upstream from the mouth. When the river discharge is greater than $400 \mathrm{~m}^{3} / \mathrm{s}$, the Gion sluice completely opens. As a result, the freshwater runoff from the Gion sluice is about half of the river discharge. Figure 1(b) shows the longitudinal profile of the bottom by an echo-sounder. The inclination of the bottom is nominal in the river channel.

\subsection{Observation methods}

Sta. A and B are located at points $2.8 \mathrm{~km}$ and $5.8 \mathrm{~km}$ upstream from the mouth, respectively. Vertical profiles of velocity and acoustic backscatter at Sta. A and B were measured by using moored aDcps (Nortek's $1.5 \mathrm{MHz}-\mathrm{NDP}$ and $2 \mathrm{MHz}-$ AqPr).

At Sta. A, salinity and temperature near the water surface and bottom were collected to examine the density stratification in addition to the aDcp measurement. The measuring points were located at $0.1 \mathrm{~m}$ depth and 0.5 meter above the bottom (mab). The cell size and the averaging time of NDP was configured to $0.25 \mathrm{~m}$ and 5 minutes, respectively. The NDP data was collected at time interval of 20 minutes. The AqPr data (cell-size $=0.15 \mathrm{~m}$, averaging time $=5$ minutes) were collected at time interval of 30 minutes. The observation was performed for one month from September 12 to December 12, 2004. 

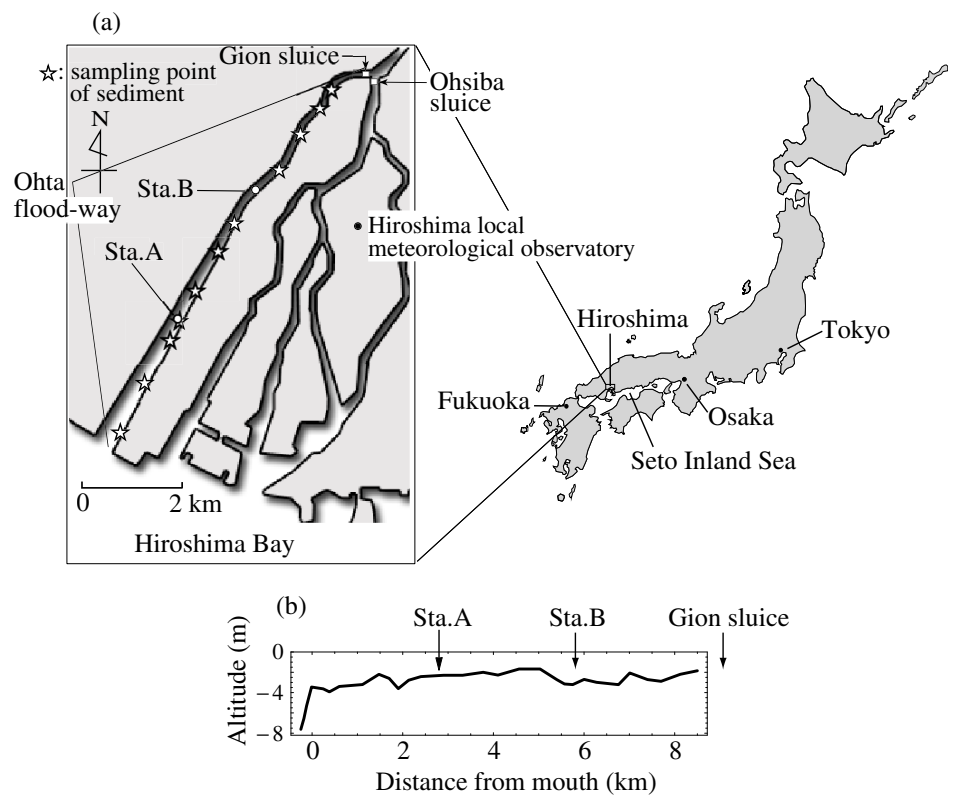

Figure 1: (a) Study area, denoting observation points; (b) bottom topography of the Ohta flood-way.

The volume scattering coefficients of aDcps, which were deduced from a sonar equation, were calibrated with water samples. Although calibration constants depend on particle size and composition for both optical and acoustic instrumentation, any error incurred due to variation in these characteristics is assumed to be less than other errors in the gravimetric sampling. Regardless of such limitations about sensitivities to particle size, the acoustic technique appears to be reliable when compared with other methods.

The surface sediments of the tidal flat, which are formed alongside the bank, were collected at lower low waters to examine the particle size distributions. The surface sediments were sampled at the eleven sampling points on the left tidal flat as shown in Figure 1(a).

\section{Results and discussion}

\subsection{Variability of stratification, velocity and SS concentration}

As shown in Figure 2(b), there were two flood incidents in the observation period. The Gion sluice was completely opened on September 24-25 and 29-30, because the river discharge was greater than $400 \mathrm{~m}^{3} / \mathrm{s}$. The stratification was examined by means of the parameter $\phi$ proposed by Simpson and Hunter [4]. The parameter $\phi$ 

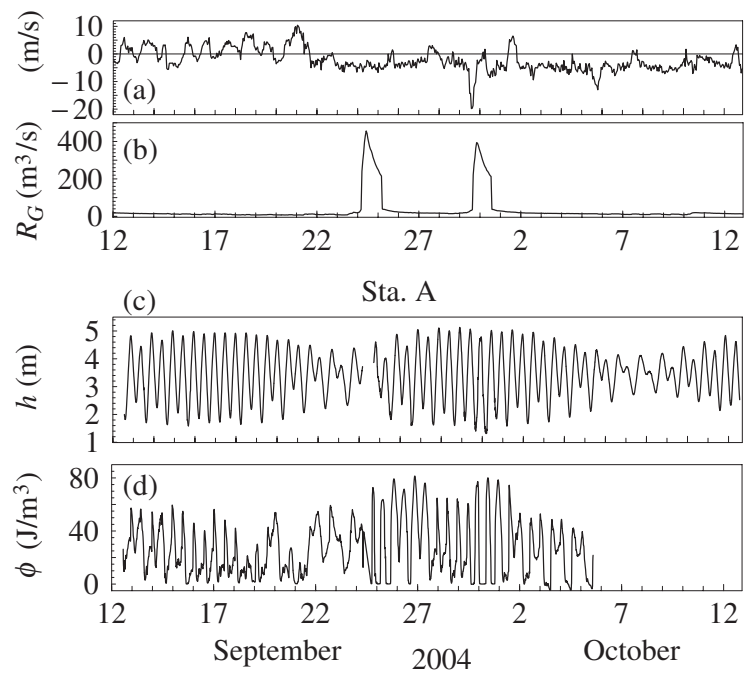

Figure 2: Temporal variations of (a) wind along flood-way, (b) freshwater discharge from Gion sluice and (c) water depth, (d) strength of stratification.

is the work required to bring about complete mixing and calculated by

$$
\phi=\frac{1}{h} \int_{-h}^{0}(\hat{\rho}-\rho) g z d z
$$

where $h$ is the water depth, $\rho$ water density, $\hat{\rho}$ mean density of water column, $z$ vertical coordinate. In the present study, $\phi$ is estimated from densities at the surface and bottom as $g h \Delta \rho / 12$, assuming the density profile is linear. Here $\Delta \rho$ is the density difference between the bottom and surface.

The temporal variation of stratification is shown in Figure 2(d). It was found that the stratification fluctuated significantly. The change of stratification is almost caused by the salinity fluctuations. During the spring tide, a semi-diurnal stratification cycle is highly visible. Moreover, the fluctuations of $\phi$ are amplified by the flood incidents. When the freshwater runoff from the Gion sluice is limited, the fluctuations are driven by tidal straining of freshwater-induced horizontal density gradient (Simpson et al [5]; Kawanisi [6]).

In addition to the short cycle of stratification, the spring-neaps mixing cycle and the variation of river discharge bring about a variation of stability with a longer period. Also, the stratification is influenced by the wind along the flood-way shown in Figure 2(a) as described later. The wind directed toward the upstream is denoted in positive sign.

The daily mean value of $\phi$ decreases with the increasing tidal range if the river discharge is constant. When the sluice is completely opened, the salinity becomes 0 through the water column around the low water. The effect of river discharge 


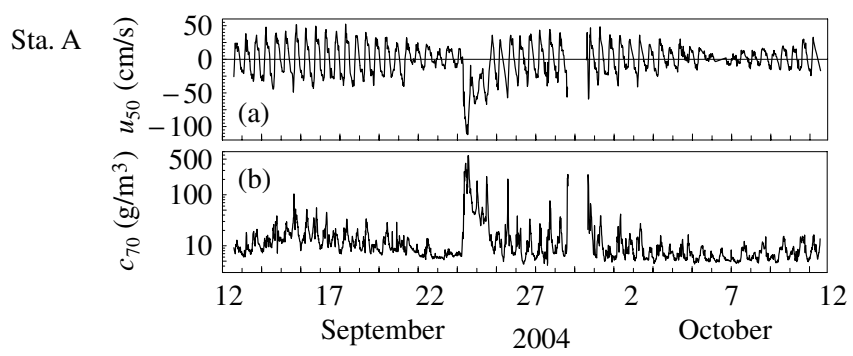

Figure 3: Temporal variations of (a) longitudinal velocity at $z / h=-0.5$ and (b) concentration of suspended sediment at $z / h=-0.7$.

$R$ on the stratification parameter $\phi$ did not result in a uniform state: when $R$ was less than $400 \mathrm{~m}^{3} / \mathrm{s}$, the mean $\phi$ increased with increasing $R$; the mean $\phi$, however, decreased with increasing $R$ when $R$ was greater than $400 \mathrm{~m}^{3} / \mathrm{s}$.

Figure 3 shows the temporal variations of streamwise velocity and concentration of suspended sediment at Sta. A. The depths of velocity and concentration in Figure 3 are $50 \%$ and $70 \%$ of the water depth, respectively. The positive sign of the velocity denotes the upstream flow. The tidal velocities are distorted from sine curves: the tidal velocities take maximum values before and after the low water slack as confirmed in Figure 4. The distortion results from the large temporal change of the water depth (cross-sectional area of stream).

When the sluice is completely opened, the velocity is negative regardless of the tidal phase because of the large runoff. The concentration of suspended sediment (SS), which is deduced from the backscatter of NDP, increases intermittently during the spring tide though the concentration is low during the neap tide. The daily mean concentration for the spring tide was twice as large as that for the neap tide. In the case of flood incident of September 24, the SS concentration exceeds $500 \mathrm{~g} / \mathrm{m}^{3}$.

In order to take a view of the closeup variation, we examined the data in two periods. The results are shown in Figures 4-6. As shown in Figure 4(e), the stratification reaches a minimum at the low water by the tidal mixing and a maximum just after the high water by the tidal straining.

From Figure 4(a), it is also found that the wind has an affect on the stratification under the smaller tide, i.e., the moderate negative wind enhances the stratification and vice versa. The velocity differences between $z / h=-0.2$ and -0.8 for the flood tide are smaller than that for the ebb tide as shown in Figure 4(f). The temporal variation of SS concentration shows peaks just before and after the low water slack (see Figure 4(g)).

The temporal variations for the large runoff are shown in the right column of Figure 4. Since the salt water in the water column is flushed out by the large runoff, the stratification vanishes around the low water (Figure 4(1)). The saltwater with the same salinity ( $30 \mathrm{psu})$ as the case of smaller runoff intrudes at the lower layer by the flood tide (Figure 4(k)). When the sluice is completely opened, the velocity 

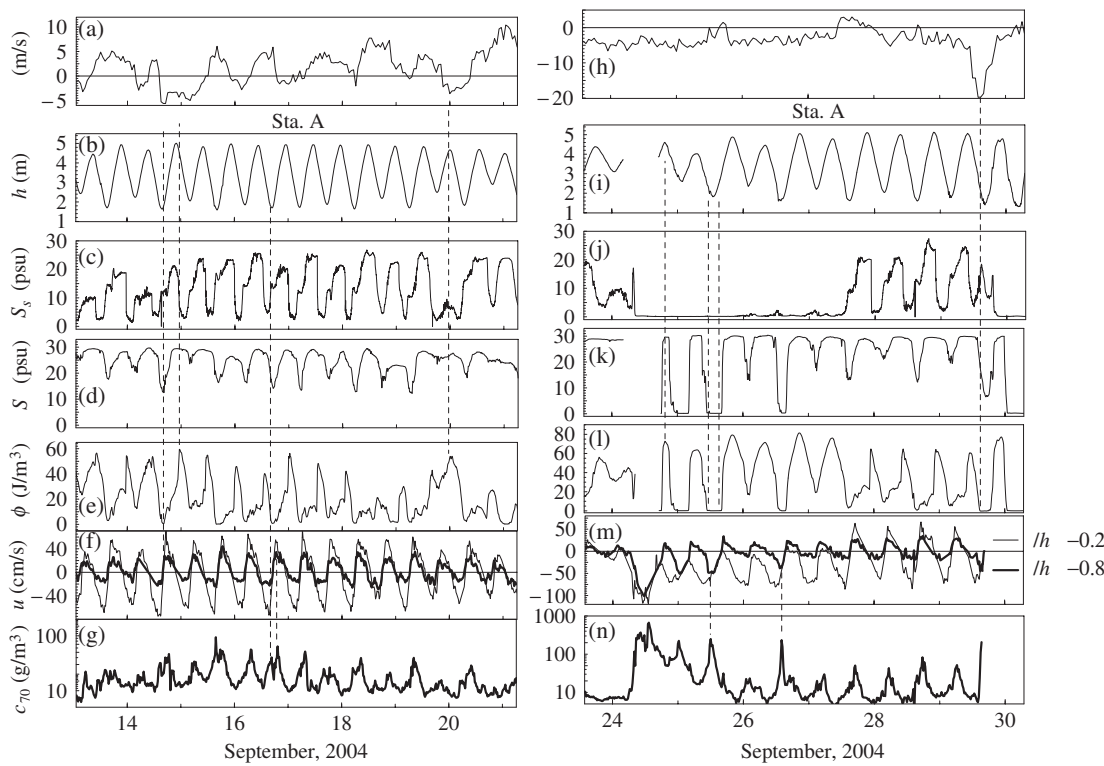

Figure 4: Temporal variations of $W, h, S_{s}$ (surface salinity), $S_{b}$ (bottom salinity), $\phi, u$, and $c$ at Sta. A.

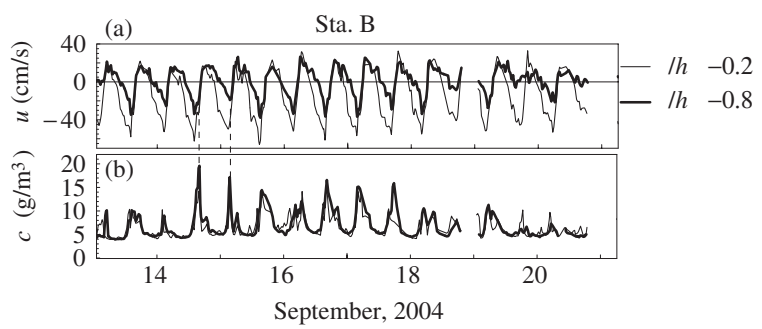

Figure 5: Temporal variations of (a) longitudinal velocity and (b) concentration of suspended sediment at Sta. B.

differences between $z / h=-0.2$ and -0.8 is small for the ebb tide (Figure $4(\mathrm{~m})$ ).

The SS concentration reaches a peak at the low water during the runoff (Figure 4(n)). On the other hand, the SS concentration at Sta. B reaches a peak at the low water even when the freshwater discharge is small as seen in Figure 5.

Figure 6 shows the space-time distribution of SS concentration. In Figure 6, the horizontal band of high concentration is found after the flood incident. It seems that the band is located around the pycnocline formed by the saltwater intrusion. 


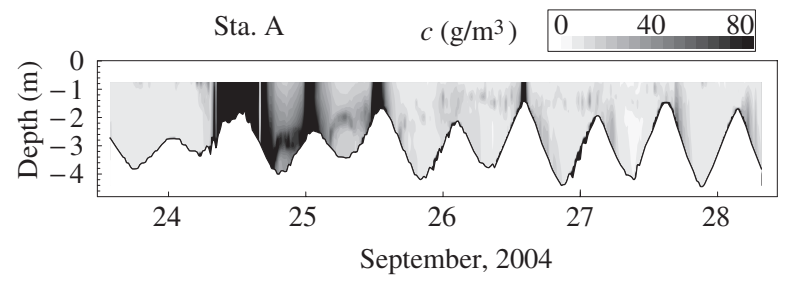

Figure 6: Space-time variation of SS concentration at Sta. A.

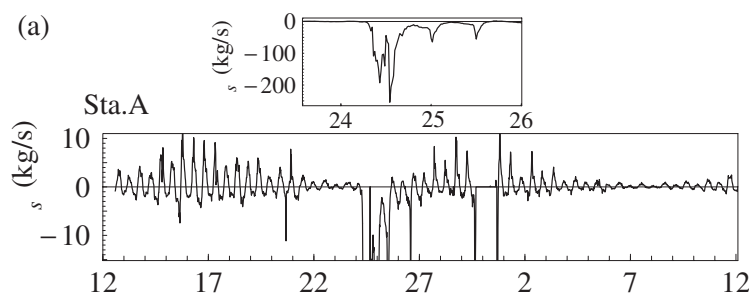

(b)

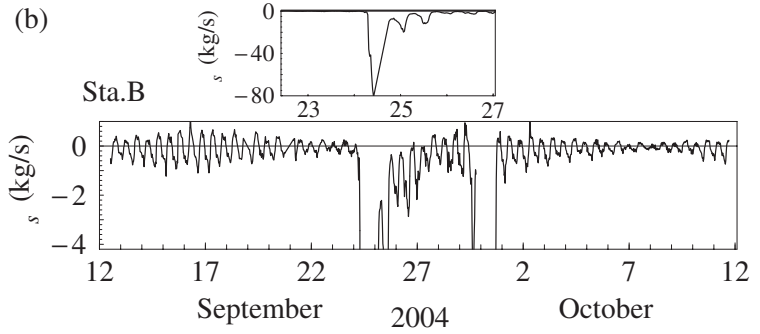

Figure 7: Temporal variations of transport SS rates of at Sta. A and B.

\subsection{Variability of transport rate of suspended sediment}

The transport rate of suspended sediment $Q_{s}$ is estimated by

$$
Q_{s}=\frac{A(h)}{z_{1}+0.9 h} \int_{-0.9 h}^{z_{1}} u(z) c(z) d z
$$

where $z_{1}$ is the depth of first cell of aDcps and $A(h)$ is the cross-sectional area of stream.

Figure 7 shows the temporal variations of $Q_{s}$ at Sta. A and B. Near the bottom, the flood velocity exceeded twice of the ebb velocity at Sta. A as seen in Figure 4(a). The tidal straining and the nonlinearity of tidal wave were main causes of the asymmetry of the tidal current and bottom shear-stress (Kawanisi [6]). Thus, the positive peak of $Q_{s}$ is greater than negative peak during the first spring tide (Figure 7(a)). As a result, the net transport of suspended sediment is upstream for the smaller freshwater discharge at Sta. A. On the contrary, the net SS transport at Sta. B is downstream for the same spring tide (Figure 7(b)). For the flood incident, 

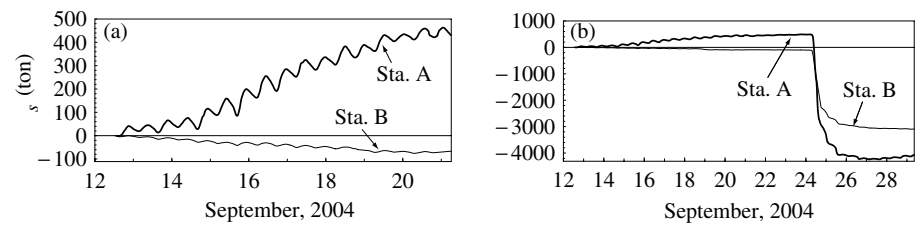

Figure 8: Amount of SS transport through the cross-sectional area of stream at Sta. A and B.

the downstream transport rate at Sta. A is considerably larger than that at Sta. B. Therefore, the sediment between Sta. A and B is eroded during the flood.

The amount of SS transport through the cross-sectional area of stream is shown in Figure 8. The amount during the first 10 days was about 400 tons and -80 tons at Sta. A and B, respectively (Figure 8(a)). Consequently, the suspended sediment accumulates between Sta. A and B for the spring tide. From Figure 8(b), which shows the cumulative transport until the second flood incident, it was found that the sediment of about 1500 tons between Sta. A and B was eroded by the first flood incident.

\subsection{Variability of tidal flat sediment}

The surface sediments of the tidal flat, which are formed alongside the bank, were collected at lower low waters to examine the particle size distributions. The investigations were conducted at times shown by arrows in Figure 9(a). On September 7 , a typhoon hits this area, so that the river discharge exceeded $2500 \mathrm{~m}^{3} / \mathrm{s}$. This flood incident considerably changed the surface sediment in the downstream region though the change of bottom form was small. Figure 9(b) shows the temporal variations of median diameter at the downstream four points. At $1.5 \mathrm{~km}$ upstream from the mouth, the median diameter decreased due to the flood. On the contrary, the median diameter increased at $2.8 \mathrm{~km}$ upstream from the mouth.

The mud contents, which are defined as fraction of fine sediment $(\leq 75 \mu \mathrm{m})$, at the four points are shown in Figure 9(c). Near the mouth $(0.5$ and $1.5 \mathrm{~km}$ upstream), it was clearly found that fine sediment was deposited by the flood. At 2.5 and $2.8 \mathrm{~km}$ points, the mud content decreases in a direction opposite to that near the mouth.

As mentioned previously, the direction of SS transport is usually upstream in the downstream region. This SS transport by tidal current brings the particle size distribution of the sediment back on track. It is found from Figure 9(b) and (c) that the sediment of tidal flat returned to its former state after about 3 months.

Figure 10(a) shows longitudinal distributions of sorting coefficient of tidal flat sediment. The sorting coefficients take maximum values around $3 \mathrm{~km}$ upstream from the mouth. It seems that this distributions are formed by the tidal current and flood incidents, i.e., during normal times, there is an upstream net transport of fine sediments from the downstream region by the tidal current and the coarse 
(a)

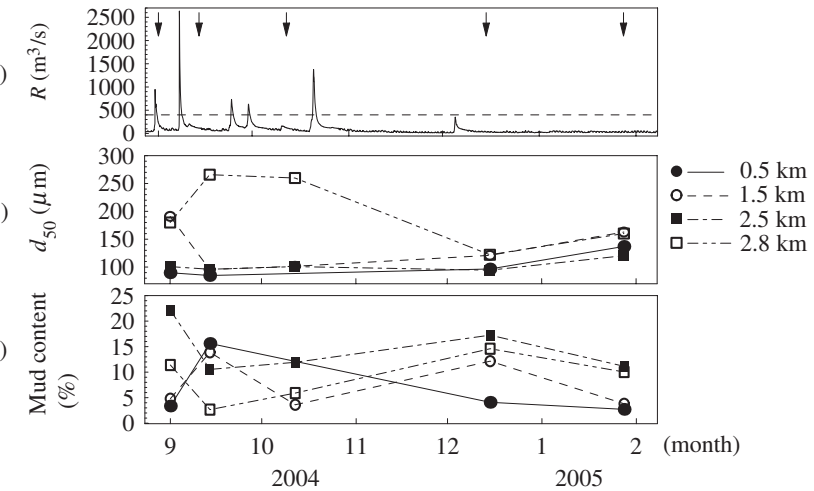

Figure 9: Temporal variations of (a) river discharge, (b) median diameter of sediment at 4 points in tidal flat, (c) mud content of sediment at 4 points in tidal flat.
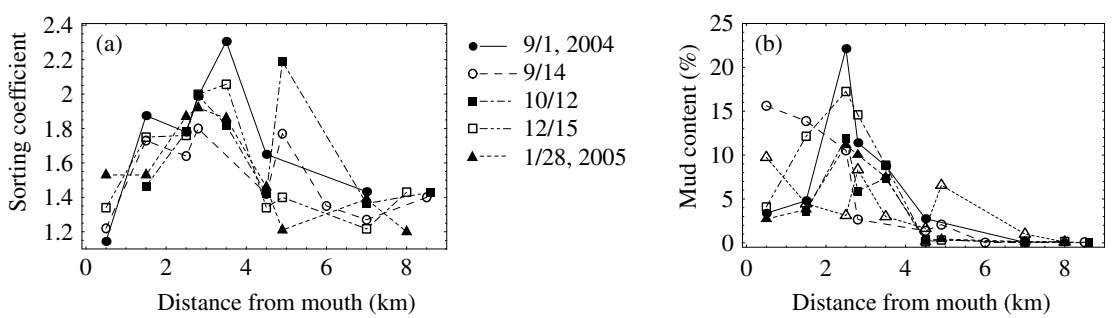

Figure 10: Longitudinal distributions of (a) sorting coefficient and (b) Mud contents of tidal flat sediment at five points of time.

sediments are dragged from upstream region by flood incidents. Moreover, it is found out that the peak of sorting coefficient distribution is moved downstream by the flood incident on September 7.

Figure 10(b) shows the longitudinal distributions of mud content. Although the mud content ordinarily reached a peak at about $2.5 \mathrm{~km}$ upstream from the mouth, it increased toward the mouth just after the flood incident on September 7.

\section{Conclusions}

The density stratification varies significantly owing to the tidal straining and the river discharge. The tidal straining brings about the stronger stratification during the ebb. The effect of river discharge on the stratification did not result in a uniform state. The daily mean stratification decreases with increasing discharge when the Gion sluice is completely opened ( $\left.>400 \mathrm{~m}^{3} / \mathrm{s}\right)$.

The suspended sediment in the flood-way was intermittently transported, i.e., the most of SS was usually transported just before and after the low water slack. 
At Sta. A, the velocity near the bottom was found to be asymmetric owing to the nonlinearity of tidal wave and tidal straining: the flood velocity was greater than ebb velocity. Consequently, the net transport of SS was upstream for the spring tide in the case of restricted freshwater discharge at Sta. A. The upstream transport increased with increasing tidal range and decreased with increasing distance from the mouth. The net transport at Sta. B, which located in $3 \mathrm{~km}$ upstream from Sta. A, is always downstream in contradiction to Sta. A. At the flood incident, the suspended sediment was significantly transported downstream around the low water and the transport rate is small around the high water.

A flood incident considerably changed the surface sediments of the tidal flat, which are formed alongside the bank. It was clearly found that fine sediment was deposited near the mouth by the flood incident. After the flood incident, the tidal current transported the fine sediment upstream. As a result, the sediment of tidal flat returned to its former state after about 3 months.

\section{References}

[1] Holdaway, G. P., Thorne, P. D., Flatt, D., Jones, S. E. \& Prandle, D., Comparison between adcp \& transmissometer measurements of suspended sediment concentration. Contin. Shelf Res., 19(1), pp. 421-441, 1999.

[2] Hill, D. C., Jones, S. E. \& Prandle, D., Derivation of sediment resuspension rates from acoustic backscatter time-series in tidal waters. Contin. Shelf Res., 23(1), pp. 19-40, 1982.

[3] Thorne, P. D., Vincent, C. E., Hardcastle, P. J., Rehman, S. \& Pearson, N., Measuring suspended sediment concentrations using acoustic backscatter devices., Mar. Geol., 98(1), pp. 7-16, 1991.

[4] Simpson, J. H. \& Hunter, J. R., Fronts in the Irish Sea. Nature, 250, pp. 404 406, 1974.

[5] Simpson, J. H., Brown, J., Matthews, J. \& Allen, G., Tidal straining, density currents, and stirring in the control of estuarine stratification, Estuaries, 13(2), pp. 125-132, 1990.

[6] Kawanishi, K., Structure of turbulent flow in a shallow tidal estuary, $J$. Hydraul. Eng., ASCE, 131(4), pp. 360-370, 2004. 